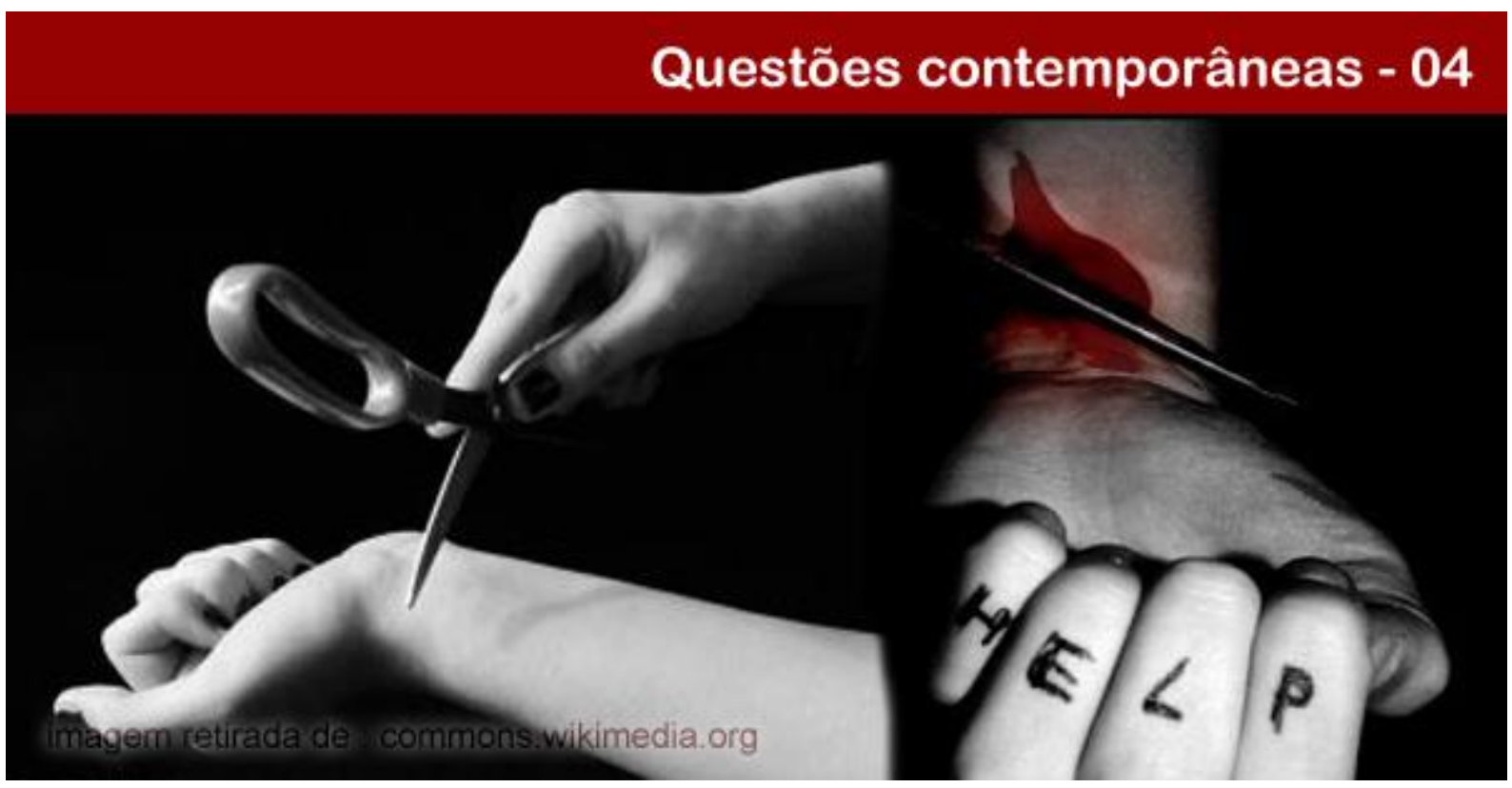

\title{
AUTOMUTILAÇÃO: O ENCONTRO ENTRE O REAL DO SOFRIMENTO E O SOFRIMENTO REAL
}

\section{Maurício de Novais Reis}

Psicanalista, filósofo e pedagogo. Especialista em Teoria Psicanalítica, mestrando em Ensino e Relações Étnico-Raciais pela Universidade Federal do Sulda Bahia.Email: contato@mauricionovais.com.

Resumo: O presente artigo trata da prática de automutilação na adolescência como reflexo da impossibilidade de estruturação da cadeia significante. Partindo de considerações sobre as origens da terminologia mutilação, aborda-se a incidência de automutilação em adolescentes do sexo feminino, nas escolas dos anos finais do ensino fundamental, baseando as hipóteses levantadas na noção de angústia formulada por Lacan. Como tentativa de resgate genealógico do conceito de automutilação, este artigo reúne as concepções médicas, psiquiátricas e psicanalíticas, fomentando a interdisciplinaridade das investigações epistemológicas. São retomados pressupostos apresentados no DSM-5 e na CID-10, para fundamentar o lugar do Real no sofrimento real da adolescência.

Palavras-chave: Automutilação. Psicanálise. Contemporaneidade. Adolescência.

\section{CUTTING: THE MEETING BETWEEN THE REAL OF SUFFERING AND REAL SUFFERING}

Abstract: The present article describes the practice of self cutting in adolescence as a return of the impossibility of structuring of the symbolic chain. On the basis of considerations about the etymological origins mutilation, discusses the incidence of cutting in female adolescents in schools of the basic education, stating the theory raised in the concept of anguish in Lacan. In an attempt to rescue the concept of self cutting, this article brings together the concepts medical, psychiatric and psychoanalytic fostering interdisciplinarity of research epistemological. Resumes premises of the DSM-5 and CID-10 to demonstrate the place of Real in the real suffering of the teenagers.

Keywords: Cutting. Psychoanalysis. Modernity. Adolescence.

\section{POLÊM!CA $\mid$ LABORE (: (3)}

Polêmica - Revista Eletrônica da Uerj - Rua São Francisco Xavier, 524, $1^{\circ}$ andar bloco D, sl.1001 • Tels.: +55 21 2334-4088/4087 • http://www.e-publicacoes.uerj.br/index.php/polemica/index http://www.labore.uerj.br • laboreuerj@yahoo.com.br 


\section{Um corte silencioso no desejo: uma introdução}

$\mathrm{Na}$ contemporaneidade, a prática de automutilação tem atraído os mais diversos olhares, sob as mais variadas concepções de entendimento. Sejam movidos pela curiosidade levantada mediante reportagens transmitidas na televisão ou mesmo em decorrência da busca de compreensão epistemológica do fenômeno, os olhares atraídos pela automutilação denunciam, estarrecidos pela densidade do real, a magnitude do mal-estar instalado na sociedade hodierna.

Interessa-se pela temática aqui investigada uma variedade cada vez maior de indivíduos. Automutilação atrai desde profissionais da psicologia, pedagogia, serviço social, medicina e enfermagem, até pais e professores, preocupados com a expansão de incidência de automutilação entre adolescentes, especialmente, nos espaços domésticos e escolares.

A palavra mutilação tem origem etimológica no idioma latino, a partir das terminologias mutilatio, mutilatum, mutilo, cujo sentido básico transmite a ideia de "ato de mutilar, cortar um membro", ou ainda "cortar, truncar ou abreviar as palavras", provocando um hiato temporal entre as palavras que compõem uma determinada fraseologia ou as partes/elementos que estruturam um determinado corpo (FARIA, 1962; TORRINHA, 1942). No inglês, geralmente a terminologia utilizada para transmitir a ideia de corte, cujo sentido é essencialmente o mesmo do latim, é cut (CORREIA, 2010). Nesta perspectiva, cutter pode ser traduzido como "cortador", ou ainda "aquele que corta", referindo-se a um sujeito que exerce ativamente a tarefa de cortar. Cutting, portanto, sugere uma ação contínua, que acontece na perspectiva de um prolongamento metodológico do transbordamento desse sujeito frente à necessidade de interrupção do objeto através do corte (DAVIS, 2005).

Neste sentido, o objeto que recebe o corte, no interior do fenômeno psicopatológico denominado de automutilação, não é outro senão o próprio corpo do sujeito, “constituído e atravessado pela linguagem" (CUKIERT, 2004, p. 233). Todavia, esse corpo atravessado pela linguagem no entrecruzamento do desejo não existe separadamente do sujeito, tampouco, dos fenômenos psíquicos que o constituem. O sujeito, na tessitura da subjetividade, constitui-se enquanto presença no registro simbólico.

No Brasil, habitualmente, designa-se de automutilação o "comportamento de autolesão voluntária", empreendido pelo indivíduo cuja finalidade é produzir cortes no próprio corpo utilizando-se de instrumentos cortantes, pontiagudos ou mesmo incendiários, sem que esteja

\section{POLÊM!CA $\mid$ LABORE}


presente a intenção consciente de suicídio (DALGALARRONDO, 2008, p. 179). Não obstante, o fenômeno de produzir modificações no próprio corpo, mediante utilização de instrumentos cortantes e/ou pontiagudos não é peculiaridade da pós-modernidade, uma vez que escritos antigos, reafirmando a atemporalidade dessa prática, proíbem terminantemente a produção de cortes no próprio corpo. Neste sentido, o Pentateuco demonstra que alguma espécie de automutilação já era conhecida na antiguidade, quando movidos pela concepção ritualística, indivíduos infringiam a si mesmos doloridos cortes ${ }^{1}$.

Este artigo não se reveste de um caráter religioso, tampouco tem como escopo a conversão daqueles que o percorrem; pelo contrário, busca insistentemente levantar os registros bibliográfico-genealógicos acerca da referida temática, organizando-os historicamente a fim de estruturar-se como documento homogêneo de investigação epistemológica, ainda que o fenômeno pesquisado se manifeste heterogêneo etiologicamente. Por outro lado, não é pretensão esgotar o tema, visto que esta seria uma pretensão permeada de autoengano. Portanto, o objetivo deste é discutir o fenômeno da automutilação numa perspectiva psicanalítica, voltada para a investigação sintomática da angústia, conforme proposta no conjunto da teorização psicanalítica.

\section{As contribuições das disciplinas do psiquismo}

A prática da automutilação tem se produzido à medida que a angústia avança insistentemente sobre o campo da subjetividade. Desta forma, faz-se necessário que investiguemos as etiologias escamoteadas pelos sintomas evidenciados nesse campo, que instalam um mal-estar no corpo para além da subjetividade; os sintomas emergem na subjetividade mediante as marcas da angústia no psiquismo, transferindo-se para o corpo através dos transbordamentos somáticos, sentidos na pele em forma de cortes que silenciam os gritos desesperados e aliviam o sofrimento.

A angústia opera uma lacuna na simbolização, isto é, uma ruptura no registro simbólico do sujeito, impossibilitando a articulação dos significantes sobre os quais se encontra sustentado todo o arcabouço subjetivo do indivíduo.

\footnotetext{
${ }^{1}$ A prática de produzir cortes no próprio corpo já era conhecida na antiga sociedade hebraica (cf. Levítico, 21, 5; Deuteronômio, 14, 1; Jeremias 16, 6), Constata-se, todavia, que o fenômeno antigo diferencia-se do moderno, pois enquanto no passado as incisões eram produzidas ritualisticamente em resposta a eventos específicos, como falecimento de indivíduos, atualmente a automutilação refere-se à impossibilidade de estruturação da cadeia significante diante do real.
}

\section{POLÊM!CA $\mid$ LABORE}

Polêmica - Revista Eletrônica da Uerj - Rua São Francisco Xavier, 524, $1^{\circ}$ andar

bloco D, sl.1001 • Tels.: +55 21 2334-4088/4087 • http://www.e-publicacoes.uerj.br/index.php/polemica/index

http://www.labore.uerj.br • laboreuerj@yahoo.com.br 
O inconsciente estrutura-se como linguagem (LACAN, 1964/1985). É, portanto, mediante a linguagem que o sujeito articula sua verdade simbólica no âmago das relações humanas. Mesmo antes do nascimento, o indivíduo encontra-se rodeado por um sistema de significações verbais e experimenta uma comunicação, um tipo de linguagem peculiar, que é o contato do corpo materno que deixa registros para o resto da vida do indivíduo. O corpo constitui, deste modo, o "primeiro meio de contato com o mundo, mesmo antes de existir um Eu, ou seja, o corpo preexiste ao Eu” (AZEVEDO; EL BIZRI, 2014, p. 4). Isso não implica em afirmar que a linguagem verbal seja de importância menor em relação à comunicação corporal, posto que o universo da linguagem verbal se encontra constituído mesmo antes da chegada da criança ao seio familiar.

Nesta perspectiva, a linguagem articula-se enquanto sistema de significação que insere o indivíduo no universo simbólico, atravessando culturalmente o corpo do sujeito. Grosso modo, a subjetividade é definida pela entrada do sujeito no campo da linguagem, passando este a engendrar um discurso sobre si mesmo, a fim de estruturar uma versão acerca de sua própria história de vida. Entretanto, a angústia sobrepõe-se à articulação dos significantes que exprimem a verdade do sujeito, provocando um transbordamento somático evidenciado no corpo. Quando faltam significantes para nomear a angústia, não raramente aparecem os transbordamentos somáticos, expressos através de cortes, perfurações e queimaduras autoinfligidas.

Por outro lado, ataca-nos a todos os importantes questionamentos acerca da automutilação. Dentre eles, podemos destacar alguns: como auxiliar pessoas que expressam no corpo, mediante atos contra si mesmos, suas angústias psíquicas? Como dar voz ao sofrimento silencioso que corta literalmente os desejos? Que competências precisam ter aqueles que se encontram em contato com indivíduos que se automutilam? Como podem as psicoterapias auxiliá-los?

Calligaris (1989) explicita que as psicoterapias operam sempre no varejo. Enquanto método psicoterapêutico, a psicanálise é uma clínica da fala, essencialmente ancorada na escuta do sujeito que sofre (FOCHESATTO, 2011). Portanto, o sujeito adoecido é, antes de qualquer coisa, um sujeito em sua singularidade, não apenas um corpo (SANTOS, 2013). Neste sentido, podemos afirmar que, embora as etiologias dos sintomas expressos através da

\section{POLÊM!CA $\mid$ LABORE}


automutilação possam se apresentar singularmente, caso a caso, faz-se necessário prestar uma escuta àqueles sujeitos cujo sofrimento impõe esses atos (LECLAIRE, 1986).

$\mathrm{Na}$ perspectiva de produzir um relato epistemológico acerca da automutilação, assim como das etiologias ocultas às sombras dos atos produzidos no corpo, este estudo sustenta que a automutilação se inscreve mediante uma linguagem peculiarmente fundamentada na angústia enquanto interdição simbólica dos significantes que estruturam o sujeito. É essa interdição simbólica que acarreta no sujeito uma lacuna angustiante, uma vez que opera um corte simbólico no sentido da existência, que não pode ser narrado devido à falta de significantes que o exprimam adequadamente na "relação essencial da angústia com o desejo do Outro" (LACAN, 2005, p. 14). Quando faltam os significantes essenciais da cadeia estruturante do sujeito, o transbordamento somático faz-se inevitável.

Assim, torna-se imprescindível retomar questões levantadas anteriormente. Como auxiliar pessoas que expressam no corpo, mediante atos contra si mesmos, suas angústias psíquicas? Como dar voz ao sofrimento silencioso que corta literalmente os desejos?

No Seminário 10, Lacan expõe a situação, lecionando que a

[...] existência da angústia está ligada a que toda demanda, mesmo a mais arcaica, tem sempre algo de enganoso em relação àquilo que preserva o lugar do desejo. Também é isso que explica a faceta angustiante daquilo que dá a essa falsa demanda uma resposta saturadora" (2005, p. 76).

Nesta perspectiva, a automutilação constitui uma resposta à mordaça imposta no desejo, que opera uma interdição dos significantes que produzem a simbolização necessária à elaboração dos conflitos intrapsíquicos.

Desta forma, respondendo à primeira das questões supracitadas, podemos dizer que a maneira mais eficiente de se auxiliar alguém que se automutila é prestar-lhe uma escuta. Não qualquer escuta, mas uma escuta revestida de empatia qualificada, cuja finalidade seja auxiliar o sujeito que sofre a construir as pontes pelas quais impreterivelmente deverá realizar a travessia da fantasia ${ }^{2}$. Assim, a escuta no interior das psicoterapias tem uma função essencial: estruturar na cadeia significante as lacunas simbólicas que operam o lugar do desejo, auxiliando o sujeito a construir significantes que atribuam sentido a essas lacunas. É

\footnotetext{
2 “A travessia da fantasia envolve que o sujeito assuma uma nova posição em relação ao Outro como linguagem e ao Outro como desejo" (FINK, 1998, p. 86). Por isso, a psicoterapia se torna tão relevante. Todavia, não se defende neste trabalho, em momento algum, a sobreposição de qualquer abordagem teórica sobre as demais. Pelo contrário, parte-se do pressuposto de que as diferentes abordagens convergem, cada uma se utilizando de sua metodologia, para o avanço das pesquisas referentes à prática de automutilação na adolescência.
}

\section{POLÊM!CA $\mid$ LABORE}

Polêmica - Revista Eletrônica da Uerj - Rua São Francisco Xavier, 524, $1^{\circ}$ andar

bloco D, sl.1001 • Tels.: +55 21 2334-4088/4087 • http://www.e-publicacoes.uerj.br/index.php/polemica/index http://www.labore.uerj.br • laboreuerj@yahoo.com.br 
necessário, portanto, um trabalho de escuta, "cujo tempo será de acordo com o desejo de cada sujeito e a avaliação de cada caso, para se identificar o sentido da automutilação e o que ela representa pulsionalmente" (ARAUJO et al, 2016, p. 512).

Todavia, esta não é tarefa fácil. Não é fácil porque envolve uma investigação clínica ampla acerca das etiologias dos sintomas. Na clínica, nos confrontamos com matizes do sofrimento cuja diversidade semiológica provoca desconforto, o que torna consideravelmente mais desafiador do ponto de vista da intervenção psicoterapêutica, pois não bastará investigar apenas o fenômeno sintomático, mas também a impulsividade e a compulsão à repetição, isto é, as forças pulsionais que operam de modo a conduzir o indivíduo repetidamente à realização do ato sintomático (REIS, 2016a). No processo de desenvolvimento da transferência, o analisando compreenderá o que está fazendo, tornando-se capaz de estruturar sua "fantasia fundamental e captar os modos pelos quais fixa o objeto que é para o Outro" (GUEGUEN, 1997, p. 106). A isso Lacan denomina de travessia da fantasia.

A automutilação representa a operação de um corte, uma descontinuidade, uma espécie de hiato no registro Simbólico do indivíduo, posto que tenha como fundamento primordial a angústia. Neste tocante específico, inferimos que a angústia expressa uma falta na semântica do desejo; falta que autentica o lugar do desejo na semântica do sujeito, implicando na constituição de uma lacuna subjetiva. Onde devia aparecer o significante essencial do sujeito, surge a descontinuidade simbólica, ou seja, a falta de significação subjetiva. Nesta perspectiva, os transbordamentos sintomáticos no corpo (físico e subjetivo) parecem inevitáveis.

Contudo, as áreas que investigam o psiquismo humano, a saber, psicologia, psiquiatria e psicanálise, bem como as variadas psicoterapias existentes na contemporaneidade, não contam com vasto material epistemológico e metodológico no tocante às etiologias, diagnóstica e tratamento (GIUSTI, 2013). Sendo limitado o número de estudos publicados acerca desse crescente fenômeno, torna-se mais desafiador acolher e tratar os pacientes afetados por esses sintomas.

Na esteira das contribuições de Calligaris (1989), nas clínicas psicoterapêuticas, a semiologia não exprime a priori as causas do sofrimento psíquico, especialmente, dos indivíduos que se automutilam. Cada caso é tratado segundo suas peculiaridades, na

\section{POLÊM!CA $\mid$ LABORE}


singularidade do discurso de cada indivíduo, bem como na relação desse indivíduo com sua história fundamental, enquanto sujeito desejante.

Esbarra-se no desejo. Pior, esbarra-se no real da impossibilidade de articulação do desejo. Portanto, esbarra-se no sujeito atravessado pelo desejo, que não consegue articular seu desejo nas malhas da significação. Destarte, a angústia se refere a um saber acerca do desejo que, não podendo ser expresso através de significantes, silencia a estrutura simbólica e produz cortes na linguagem. Os cortes produzidos na linguagem transbordam pulsionalmente no lugar de cortes somáticos expressos, fisicamente, na constituição imagética do corpo do sujeito.

Portanto, o corte expresso no corpo do sujeito não tem como finalidade chamar atenção dos pais, professores ou adultos em geral. Não constituem uma "birra" de adolescentes revoltados sem causa. A prática de automutilação objetiva, para $75 \%$ dos entrevistados por Giusti (2013), como uma tentativa de "parar sensações ruins". Dentre os entrevistados, $70 \%$ responderam que o objetivo é "aliviar sensação de vazio" ou “autopunição". Somente 7,5\% disseram querer chamar atenção (GIUSTI, 2013, p. 77).

A incidência de automutilação (ou cutting, como alguns preferem) surge como uma alternativa à dor psíquica que acomete o indivíduo, levando-o à passagem ao ato, isto é, uma espécie de ruptura no quadro da fantasia, cujo movimento se evidencia na autoagressão (ROUDINESCO, 1998). Entretanto, questiona-se, especialmente dentre os profissionais da educação, como a produção de corte na carne pode aliviar, ainda que momentaneamente, o sofrimento psíquico do sujeito. Fisiologicamente, isso pode ser explicado porque no momento do ferimento, o sistema nervoso central libera uma quantidade determinada de endorfina, um hormônio cuja finalidade é proporcionar sensação de bem-estar, funcionando como analgésico que reduz a sensação de dor.

$\mathrm{Na}$ prática clínica com adolescentes, os psicoterapeutas frequentemente se deparam com expressões que revelam o real do sofrimento:

Foi como se de repente tivesse uma enorme dor batendo às portas de minha consciência: um sentimento arrebatador, extremo, e sabia que se deixasse, eu entraria em colapso. E então, justamente quando pensava que não tinha controle sobre o que aconteceria, eu percebi duas coisas: primeiro que a dor emocional estava desaparecendo e que, não ia consumir-se, e o segundo era que eu estava pregando a chave de fenda, e estava literalmente me atacando, e que a dor física que eu estava produzindo era melhor do que qualquer um dos sedativos que me deram no hospital (HOBAN, 2014, p. 164).

\section{POLÊM!CA $\mid$ LABORE}

Polêmica - Revista Eletrônica da Uerj - Rua São Francisco Xavier, 524, $1^{\circ}$ andar

bloco D, sl.1001 • Tels.: +55 21 2334-4088/ 4087 • http://www.e-publicacoes.uerj.br/index.php/polemica/index

http://www.labore.uerj.br • laboreuerj@yahoo.com.br 
Embora figurem numa obra ficcional, estas palavras demonstram o fenômeno em que a dor física seda a dor emocional, tornando a primeira preferível à segunda. Nesta perspectiva, a automutilação torna-se uma válvula de escape às dores psíquicas que afetam os indivíduos. Por isso o fenômeno autolesivo geralmente passa a se repetir com determinada regularidade antes de iniciada a intervenção psicoterapêutica.

As psicoterapias, especialmente a psicanálise, sustentam a verdade do sujeito atravessado pela linguagem no entrecruzamento simbólico do desejo. Não se trata aqui de uma verdade epistêmica, absoluta, positivista, mas da verdade do sujeito que sofre. Assim, na prática clínica com adolescentes, o sofrimento sintomático revela a fragilidade subjetiva desses pacientes e, por isso, deve ser considerado mais seriamente. Não raramente os cortes produzidos na carne possuem significações que ultrapassam as interpretações fenomenológicas, porque representam - ou visam a representar - as marcas primariamente produzidas no psiquismo.

Diversamente das clínicas fenomenológicas e descritivas, a saber, a medicina e a psiquiatria, principalmente, a psiquiatria entrincheirada nos saberes biomédicos cujo estatuto ontológico fundamenta-se na descrição semiológica e aplicabilidade farmacológica, as psicoterapias partem de uma concepção clínica baseada no discurso do sujeito. Neste ponto específico, as escoriações possuem valor de sintoma (REIS, 2016b).

Não obstante, os saberes produzidos no âmbito da psiquiatria são importantes, sobretudo, porque constituem uma construção estatística e diagnóstica dos fenômenos e transtornos psicopatológicos.

O Manual Diagnóstico e Estatístico de Transtornos Mentais - DSM, na sua quinta edição, enquadra a automutilação no campo dos fenômenos sintomáticos que podem, comorbidamente, manifestar-se em diversos transtornos conhecidos, desde os Transtornos do Neurodesenvolvimento (APA, 2014, p. 78, 80), passando pelos Transtornos Dissociativos de Identidade (comportamento autolesivo predominante em mulheres, APA, 2014. p. 294, 299), até o Transtorno de Personalidade Borderline (APA, 2014, p. 664).

A Classificação Estatística Internacional de Doenças e Problemas Relacionados à Saúde - CID-10, por sua vez, insere no transtorno de personalidade com instabilidade emocional, subdividido em transtorno da personalidade agressiva, borderline e explosiva o "comportamento autodestrutivo, compreendendo tentativas de suicídio e gestos suicidas"

\section{POLÊM!CA $\mid$ LABORE}


(OMS, 2008, F60.3). Por outro lado, a automutilação é especificamente mencionada como produção deliberada ou simulação de sintomas ou de incapacidades, físicas ou psicológicas, tratando-se de sintoma simulado, como na Síndrome de Münchhausen (OMS, 2008, F68.1). Embora as hipóteses previstas nos manuais indiquem a falta de compreensão específica quanto aos fenômenos analisados, fazem-se importantes à medida que catalogam os sintomas conforme sua ocorrência estatística. Todavia, tornam-se incompletos na medida mesma em que, buscando uma causa originária amparada no estatuto do discurso biomédico e biocientífico, deparam-se com a descontinuidade ontológica da semiologia clínica, o que dificulta inequivocamente a identificação categórica da etiologia (SANTOS, 2013).

No que se refere a pacientes borderline, geralmente denominados dentro da estrutura psicopatológica psicanalítica de pacientes-limites, estados-limites, pacientes-limítrofes ou fronteiriços, frequentemente manifestam fantasias de automutilação, descontrole dos impulsos e agressividade:

A agressividade é comum, podendo o paciente ter um histórico de refregas e
discussões com familiares ou com estranhos (brigas e confusões na rua são
frequentes). Em geral, são fruto de explosões em situações contornáveis aos olhos
do observador, mas que o borderline não consegue evitar. Comumente, após o
episódio agressivo, arrependem-se. Alguns filmes e literatura exploram estas
características do borderline, embora assassinatos sejam muito menos frequentes que
o suicídio, a autoagressão ou a automutilação (HEGENBERG, 2009, 62).

Nesta perspectiva, os sintomas apresentados indicam duas coisas relevantes: primeiro, na impossibilidade biocientífica de identificar e diagnosticar peremptoriamente, segundo o modelo clínico biomédico, os fenômenos ocorridos no psiquismo humano. Segundo, não havendo uma teoria específica das causas, torna-se difícil estabelecer terapêutica (farmacológica ou não) que resulte na cura definitiva dos transtornos. Neste sentido, torna-se necessário repetir: as psicoterapias operam no varejo, estimulando a estruturação de um discurso singular do paciente, no qual este assume a posição de sujeito atravessado pela linguagem, articulando-se como sujeito desejante.

Existe "um mal-estar atormentador" instalado no interior do sujeito contemporâneo (FREUD, 1996, p. 138). Esse mal-estar ocasiona o surgimento de sintomas os mais variados, desde a tricotilomania, ansiedade, neuroses obsessivas, automutilação não suicida e até suicídio. Verifica-se agieren (para utilizar a expressão freudiana), ou seja, um agir impulsivo (LAPLANCHE, 1991, p. 44). Faz-se presente também a compulsão à repetição dos sintomas,

\section{POLÊM!CA $\mid$ LABORE}


especialmente os sintomas automutilatórios que, na busca desesperada de alívio da dor que provoca cortes dolorosos no corpo subjetivo, imaginário, geram cortes profundos no corpo físico, real.

Dois são os corpos que sofrem as agressões autoinfligidas, um real e outro imaginário. Forbes $(2004$, p. 2) complementa:

\footnotetext{
Enquanto Körper é o corpo material, mensurável, com que lida o médico, Leib é o corpo-corpo, vida, que não se mede no espaço cartesiano e com o qual, aliás, não podemos operar através de instrumento algum. Nenhum metro se oferece entre nós e o Leib. O Leib é determinante do Körper.
}

Certamente, mal-estar não tem faltado à contemporaneidade, cujas dúvidas não são mais as mesmas do passado. As transformações empreendidas pela pós-modernidade na moral, na ética e no comportamento em geral, transformaram o mundo outrora ordenado hierarquicamente numa horizontalização do laço social. As transformações ocorridas no decurso das últimas décadas, com o advento da globalização, tornaram o homem um ser desbussolado, perdido, desnorteado (FORBES, 2005). "O homem desbussolado desconhece, cada vez mais, o real da estrutura que o determina" (FORBES, 2010, p. 20), especialmente, porque o real da estrutura que determina o sujeito pós-industrial determina-o também no campo da angústia

Quando Lacan fala sobre a angústia, no Seminário 10, distingue a angústia de todos os outros afetos, dizendo que, na análise e na vida, a angústia é o único afeto que não engana, ou ilude. Ele mostra como a angústia se liga àquilo que chama de real. É uma função que se pode não compreender, mas que não engana (MILLER, 1997, p. 24).

Nesta perspectiva, a angústia pode estar intimamente relacionada à incidência de automutilação na adolescência. As transformações na moral provocaram, sobretudo, um desbussolamento do desejo, propiciando o surgimento de uma nova modalidade de angústia. Enquanto Freud (1996), no interior de suas investigações, apontava para o homem traumatizado, a psicanálise pós-moderna depara-se com o real do desbussolamento resultante da horizontalização do laço social.

Suspeita-se, portanto, que a incidência de automutilação e autolesão na adolescência aponta para um novo paradigma de angústia, que não mais a angústia do homem traumatizado, mas, especialmente, a angústia do sujeito cujas possibilidades são tantas que se

\section{POLÊM!CA $\mid$ LABORE}


encontra fortemente petrificado frente às possibilidades de um laço social relativizado, desprovido da rigidez hierárquica, como o vigente na pós-modernidade.

\section{$O$ real do sofrimento e o sofrimento real instalado na rede municipal de ensino de}

\section{Teixeira de Freitas}

A rede municipal de ensino de Teixeira de Freitas, município localizado no Extremo Sul da Bahia, cuja população estima-se em cerca de 160 mil habitantes, tem experimentado na pele o real do sofrimento psíquico.

No decorrer do ano letivo de 2016, casos de automutilação foram detectados por coordenadores e professores nas unidades de ensino da segunda etapa do ensino fundamental. Numa escola após outra, os casos foram identificados para desalento dos profissionais. Desta maneira, instalou-se o mal-estar no exercício dos professores que, não sabendo como encaminhar os procedimentos necessários, recorreram à Secretaria Municipal de Educação e Cultura em busca de auxílio. A Secretaria, por sua vez, na tentativa de compreender a extensão do problema, recorreu ao Departamento de Psicologia da Faculdade Pitágoras de Teixeira de Freitas, na qual o curso de Psicologia é ofertado, e que, portanto, conta com pesquisadores.

Neste cenário, nasceu a parceria entre a Secretaria Municipal de Educação e Cultura, Faculdade Pitágoras de Teixeira de Freitas e Sociedade Brasileira de Psicanálise e Psicoterapias com o objetivo de debater as questões envolvidas no fenômeno da automutilação, bem como a etiologia dos processos de autolesão praticada na adolescência.

Instalado o mal-estar no âmago do processo educacional, os atores desse processo passaram a buscar subsídios a fim de compreender o fenômeno. Todavia, em decorrência da escassa bibliografia científica publicada no Brasil, coordenadores pedagógicos, professores, estudantes de psicologia e psicanalistas teixeirenses reuniram-se para debater as possíveis causas do fenômeno. As mais variadas hipóteses de causalidade foram levantadas pelo grupo, desde o impacto das mudanças sociais que "alteram as experiências subjetivas individuais" (GURFINKEL, 2011, p. 35) até a suposta influência das mídias sociais no comportamento dos adolescentes, uma vez que as redes sociais se encontram repletas de comunidades sobre a referida temática - porém sem qualquer confirmação plausível (GIUSTI, 2013). A

\section{POLÊM!CA $\mid$ LABORE}


possibilidade de transtorno de personalidade borderline também chegou a ser considerada, embora não confirmada mediante escuta terapêutica (CHENIAUX JUNIOR, 2015).

Dentre as vinte escolas que ofertam a segunda etapa do ensino fundamental no município de Teixeira de Freitas, três se localizam nos distritos e zona rural, enquanto dezessete estão situadas na sede. Da totalidade das unidades educacionais localizadas na sede, nove detectaram a ocorrência de automutilação entre adolescentes, sendo, até o presente momento, público pertencente ao sexo feminino. No tratamento dos dados levantados, a predominância de ocorrência do fenômeno entre indivíduos do sexo feminino surpreendeu a equipe de pesquisadores, visto que os números podem indicar um paradigma peculiar de angústia incidente no feminino.

No total, foram detectados 27 casos de automutilação, cujas idades variam entre 12 e 17 anos. Até o presente momento, nenhum caso de incidência em indivíduos do sexo masculino foi relatado. Obviamente, isso não significa necessariamente que, no universo de dezessete escolas que ofertam as séries finais do ensino fundamental na sede do município, estes sejam todos os casos existentes. Pode-se inferir que haja casos que ainda não foram detectados e, portanto, não podem ser confirmados, bem como adolescentes que tenham abandonado a prática de automutilação após o início do tratamento psicoterapêutico.

O Projeto Silêncios Quebrados, resultante da reunião de coordenadores pedagógicos, professores, estudantes de psicologia, psicólogos e psicanalistas, que objetiva a detecção e encaminhamento dos casos de automutilação nas escolas de ensino fundamental, encontra-se momentaneamente paralisado devido à mudança de gestão da Secretaria Municipal de Educação e Cultura. A expectativa é que o estudo seja retomado assim que o departamento pedagógico da secretaria de educação estiver plenamente reestruturado. Por causa da paralisação do projeto, as escolas ficaram sem um feedback acerca do acompanhamento psicológico realizado pelas instituições parceiras, principalmente, o departamento de psicologia da Faculdade Pitágoras. Portanto, no presente momento não se sabe informar se as famílias continuam conduzindo as adolescentes para o acompanhamento psicológico/psicanalítico.

\section{POLÊM!CA $\mid$ LABORE}




\section{A Clínica com adolescentes}

Zimerman (2004, p. 360) explica que "o primeiro aspecto que deve ser ressaltado é o que diz respeito aos atributos pessoais do terapeuta de adolescentes”. Segundo o autor, para ser terapeuta de adolescentes é condição mínima indispensável gostar de adolescentes. Se assim for, terá melhores condições de lograr êxito na manutenção do que denomina aliança terapêutica.

Independentemente da abordagem teórico-metodológica adotada pelo profissional desde o psiquiatra de adolescentes que atende no Centro de Atenção Psicossocial, o psicólogo clínico que atende na instituição de ensino ou consultório particular, o psicanalista que atende adolescentes no seu consultório -, as palavras de Zimerman acarretam um sentido essencial à prática com adolescentes.

Até mesmo aos professores - que normalmente são os primeiros a perceberem "algo diferente" com seus alunos adolescentes, encaminhando-os à coordenação pedagógica do estabelecimento de ensino para as devidas providências e encaminhamentos - gostar de adolescentes é condição sine qua non para a realização de um trabalho eficiente.

Referindo-se à condição de adolescente, Sônia Albert esclarece:

Digo que a própria adolescência é uma escolha do sujeito. Ele pode escolher atravessá-la, mas pode também não escolhê-la. Entendo que entrar na adolescência já é, per se, uma escolha — o sujeito escolhe assumir o desligamento dos pais (ALBERT, 2010, p. 46).

Indubitavelmente, a adolescência constitui-se como um complexo período de transição. Atravessar a adolescência implica abandonar a identidade infantil para assumir, ainda que parcialmente, uma identidade de sujeito adulto, cujas responsabilidades se tornam mais sérias. Ao escolher atravessá-la, o sujeito adolescente pode deparar-se com a angústia própria dessa travessia, uma espécie de receio de desintegração. Por outro lado, escolhendo não atravessá-la, o sujeito adolescente depara-se com a equivalência da angústia de castração, ou seja, a interdição do seu desejo de desenvolvimento. Certamente, atravessar a adolescência não constitui uma tarefa simples. Isso porque a adolescência "como escolha do sujeito implica pagar o preço do desligamento dos pais, assumir que só é possível contar com o Outro em nível simbólico" (ALBERT, 2010, p. 46).

Nesta perspectiva, a automutilação costuma surgir como "último recurso" à angústia produzida pelo desligamento dos pais e da própria identidade pueril, como resposta ao

\section{POLÊM!CA $\mid$ LABORE}

Polêmica - Revista Eletrônica da Uerj - Rua São Francisco Xavier, 524, $1^{\circ}$ andar

bloco D, sl.1001 • Tels.: +55 21 2334-4088/4087 • http://www.e-publicacoes.uerj.br/index.php/polemica/index

http://www.labore.uerj.br • laboreuerj@yahoo.com.br 
fatiamento do corpo no nível imaginário. Os cortes produzidos no corpo frequentemente aliviam a dor psíquica que atormenta o sujeito. Desta forma, uma escuta qualificada pode contribuir sobremaneira para o auxílio do sujeito que sofre a produzir elaborações verdadeiramente proveitosas no tocante à descoberta do próprio ser, isto é, a descoberta dos corpos dos quais o indivíduo é constituído.

Juan David Nasio (2009, p. 55) propõe a seguinte interpretação:

O eu é um sentimento, o sentimento de existir, o sentimento de ser você. Um sentimento eminentemente subjetivo porque fundado sobre o vivido igualmente subjetivo de nossas imagens corporais. Considero, pois, o eu uma entidade essencialmente imaginária cunhada por todas as nossas ignorâncias, erros e miragens que confundem a percepção que fazemos de nós mesmos.

As disciplinas que investigam o psiquismo, conhecedoras da complexidade do corpo físico e psíquico - devem estabelecer estratégias de diálogos intersetoriais e interdisciplinares com o fito de combater o mal-estar instalado no seio da pós-modernidade, que provoca nos sujeitos adolescentes o completo desbussolamento frente à vida. $\mathrm{O}$ sofrimento vivenciado por esses sujeitos no corpo imaginário não raramente produz transbordamentos somáticos à medida que refletem no corpo real.

Diante desta realidade, a função da clínica é garantir, pelo menos, as condições mínimas de escuta, empatia e tratamento que auxilie o sujeito na reelaboração de sua cadeia significante, reconstruindo a semântica do seu desejo.

Não obstante a psiquiatria se apresente enquanto clínica descritiva e fenomenológica, o que muitas vezes acaba se chocando com a concepção de saúde mental sustentada pelo discurso psicanalítico e psicológico, não se pode prescindir de suas contribuições para o campo do psiquismo humano. Pelo contrário, casos existem de sujeitos para os quais a utilização de terapêutica medicamentosa se apresenta como condição fundamental, associada ao acompanhamento psicoterapêutico.

Em virtude da complexidade da subjetividade humana, resultado das múltiplas vivências empreendidas pelos indivíduos, as disciplinas do psiquismo se tornam cada dia mais relevantes para a humanidade, inclusive, no tocante ao tratamento do sujeito pós-moderno, desbussolado e desorientado frente à vida, que busca nas cicatrizes do corpo as coordenadas da cartografia para o encontro definitivo com o seu eu.

\section{POLÊM!CA $\mid$ LABORE}




\section{Considerações finais}

Diante dos contornos delineados no decorrer deste artigo, verifica-se que a prática de automutilação não é recente, mas recorrente na história da humanidade. Entretanto, se na antiguidade, os indivíduos se feriam no cumprimento de atos ritualísticos, hoje os ferimentos autoinfligidos não exigem, necessariamente, um ritual. Inscrevem-se, por seu turno, enquanto resposta ao sofrimento psíquico instalado nas tessituras da pós-modernidade, provocando uma "falha" no processo de significação. O sofrimento real revela algo que está para além da concretude ôntica do ser, a saber, a subjetividade, cuja densidade insustentável do Real provoca lacunas na simbolização, extraviando o sentido dos significantes que sustentam o edifício simbólico do sujeito, ou seja, ameaçando sua própria condição de sujeito atravessado pela linguagem. Assim, a conjuntura em que a automutilação ocorria na antiguidade difere-se sistematicamente do contexto nos dias atuais, o que instala a automutilação no interior de um fenômeno contemporâneo.

O entrecruzamento dos desejos no sujeito desbussolado, resultado de um laço social horizontalizado próprio deste período em que vivemos, interpõe uma lacuna no âmbito do Simbólico, desarticulando os significantes fundamentais do sujeito, os quais, articulados, produziriam, no indivíduo, o processo de significação e sentido. Esta lacuna opera, nos indivíduos e, especialmente, nos indivíduos adolescentes, o desbussolamento diante a vida.

Constata-se, desta maneira, a incidência de automutilação na adolescência enquanto retorno do Real, como aquilo que não cessa de não se inscrever, manifestado numa "falha" do processo de simbolização. Quando faltam os significantes que sustentam a estrutura do sujeito e corta-se profundamente a subjetividade, os cortes no corpo real parecem se tornar inevitáveis. Observa-se, portanto, o inalcançável do discurso, um sofrimento que não pode ser formulado em palavras.

Todavia, neste artigo buscou-se analisar o fenômeno da automutilação não no lugar de uma psicopatologia ou doença, mas enquanto acometimento fenomênico de uma falta-a-ser no lugar onde operam os significantes que estruturam o sujeito. Assim, trata-se, principalmente, de uma tentativa de levantamento e análise do sofrimento psíquico na adolescência mediante uma genealogia da manifestação sintomática. Sim! Neste artigo, constata-se que a automutilação surge enquanto manifestação semiológica de variados transtornos catalogados no DSM-5, bem como na CID-10. Todavia, o que nos interessa não pode ser reduzido à

\section{POLÊM!CA $\mid$ LABORE}


simples estatística, mas perpassa o campo psiquiátrico e desemboca nos mais variados campos. A automutilação, qual um espectro que ronda a adolescência, acontece também na escola, preocupando pais, professores, coordenadores pedagógicos e demais profissionais da educação. Os casos relatados demonstram a preocupação dos profissionais da educação no tocante à escalada da automutilação na idade escolar.

O sofrimento expresso no corpo imaginário transborda sintomaticamente para o corpo real. Essa compreensão revela duas coisas importantes que precisam ser consideradas: a primeira delas se refere à impossibilidade de cura utilizando-se apenas de terapêutica farmacológica. Caso a psicofarmacologia detivesse esse poder, os transtornos mentais estariam erradicados. A segunda coisa que deve ser considerada é o fator humano, relacional, que provoca nos indivíduos o aparecimento do sujeito. Tornar-se sujeito relaciona-se primordialmente com a qualidade do affectus, ou seja, como somos afetados pelo Outro. Nesta perspectiva, as psicoterapias ocupam lugar importantíssimo.

Portanto, encontra-se constatado, pelo menos parcialmente, que o ato automutilatório opera um corte, um entrecruzamento, nos dois corpos que constituem o eu: Leib e Körper. Quando Leib sofre a angústia do desbussolamento, devido à desarticulação dos significantes fundamentais para o sujeito pós-moderno, Körper sofre os transbordamentos sintomáticos que constituem tentativas de fuga do sofrimento psíquico. Por isso, a fim de que reestruturem seu discurso frente o Real, torna-se ainda mais urgente prestar uma escuta qualificada aos adolescentes.

\section{Referências}

ALBERT, Sônia. O adolescente e o Outro. 3. ed. Rio de Janeiro: Zahar, 2010.

AMERICAN PSYCHIATRIC ASSOCIATION. DSM-5: manual diagnóstico e estatístico de transtornos mentais. 5. ed. Porto Alegre: Artmed, 2014.

ARAUJO, Juliana Falcão Barbosa de et al. O corpo na dor: automutilação, masoquismo e pulsão. Revista Estilos da Clínica, São Paulo, v. 21, n. 2, maio/ago. 2016.

AZEVEDO, Márcia M. A. EL BIZRI, Zaíra R. Self Cutting: uma abordagem psicanalítica sobre os transbordamentos pulsionais do corpo, 2014. Disponível em:

<http://www.psicopatologiafundamental.org/uploads/files/vi_congresso/Mesas\%20Redondas/95.3.pdf>. Acesso em: 02 ago. 2017.

BÍBLIA, Português. A Bíblia Sagrada: Nova Versão Internacional [traduzida pela comissão da Sociedade Bíblica Internacional]. São Paulo: Editora Vida, 2000.

\section{POLÊM!CA $\mid$ LABORE}


CALLIGARIS, Contardo. Introdução a uma clínica diferencial das psicoses. Porto Alegre: Artes Médicas, 1989.

CORREIA, Anderson. Inglês: dicionário escolar. Blumenau: Vale das Letras, 2010.

CHENIAUX JUNIOR, Elie. Manual de psicopatologia. 5. ed. Rio de Janeiro: Guanabara Koogan, 2015.

CUKIERT, Michele. Considerações sobre corpo e linguagem na clínica e na teoria lacaniana. Psicologia USP, 2004, 15(1/2), $225-241$.

DALGALARRONDO, Paulo. Psicopatologia e semiologia dos transtornos mentais. Porto Alegre: Artmed, 2008.

DAVIS, Jeanie Lerche. Cutting \& Self-Harm: Warning Signs and Treatment. 2005. Disponível em: <http://www.webmd.com/mental-health/features/cutting-self-harm-signs-treatment>. Acesso em: 02 ago. 2017.

FARIA, Ernesto (Org). Dicionário Escolar Latino-Português. Brasília: Campanha Nacional de Material de Ensino, 1962.

FINK, Bruce. O sujeito lacaniano: entre a linguagem e o gozo. Tradução de: Maria de Lourdes Sette Câmara. Rio de Janeiro: Jorge Zahar Ed., 1998.

FOCHESATTO, Waleska P. Farenzena. A cura pela fala. Revista Estudos de Psicanálise, Belo Horizonte, MG, s/v, n. 36, dez. 2011.

FORBES, Jorge. As exposições clínicas: além das teorias e dos protocolos, a diferença clínica é dada por quem trata. Seminário de Jorge Forbes, 2004.

A psicanálise do homem desbussolado - as reações ao futuro e o seu tratamento. Opção Lacaniana: Revista Brasileira Internacional de Psicanálise, São Paulo, n. 42, p. 30-33, fev. 2005. Disponível em: <http://www.jorgeforbes.com.br/index.php?id=115>. Acesso em: 13 julho 2017.

Inconsciente e Responsabilidade. [Tese de doutorado]. Rio de Janeiro: UFRJ, 2010.

FREUD, S. (1906 [1905]). Minhas teses sobre o papel da sexualidade na etiologia das neuroses. Edição Standard Brasileira das Obras Psicológicas Completas, vol. VII. Rio de Janeiro: Imago, 1996.

(1930 [1929]) O mal-estar na civilização. Edição Standard Brasileira das Obras Completas, vol. XXI. Rio de Janeiro: Imago, 1996.

GIUSTI, Jackeline Suzie. Automutilação: características clínicas e comparação com pacientes com transtorno obsessivo-compulsivo. 2013. Tese (Doutorado em Ciências) - Faculdade de Medicina, Universidade de São Paulo, São Paulo, 2013.

GUEGUEN, Pierre-Gilles. A transferência como logro. In: FELDSTEIN, Richard; FINK, Bruce; JAANUS, Maire (orgs.). Para ler o Seminário 11 de Lacan: os quatro conceitos fundamentais da psicanálise. Rio de Janeiro: Jorge Zahar Ed., 1997.

GURFINKEL, Decio. Adicções: paixão e vício. São Paulo: Casa do Psicólogo, 2011.

HEGENBERG, Mauro. Borderline. 6. ed. São Paulo: Casa do Psicólogo, 2009.

HOBAN, Julia. Willow: É Difícil Manter um Segredo Quando Ele Está Escrito por Todo o seu Corpo. São Paulo: Leya Brasil, 2014.

\section{POLÊM!CA $\mid$ LABORE}


LACAN, Jacques. O Seminário, livro 10: a angústia. Rio de Janeiro: Jorge Zahar Ed., 2005.

[1964]. O Seminário, livro XI: Os quatro conceitos fundamentais da psicanálise. $2^{\text {a }}$ ed. Rio de Janeiro: Jorge Zahar Editor, 1985.

LAPLANCHE, Jean. PONTALIS, J-B. Vocabulário da Psicanálise. São Paulo: Martins Fontes, 1991.

LECLAIRE, Serge. Psicanalisar. 2. ed. São Paulo: Perspectiva, 1986.

MILLER, Jacques-Alain. Contexto e conceitos. In: FELDSTEIN, Richard; FINK, Bruce; JAANUS, Maire (orgs.). Para ler o Seminário 11 de Lacan: os quatro conceitos fundamentais da psicanálise. Rio de Janeiro: Jorge Zahar Ed., 1997.

NASIO, J.-D. Meu corpo e suas imagens. Rio de Janeiro: Jorge Zahar Ed., 2009

ORGANIZAÇÃO MUNDIAL DA SAÚDE. CID-10: Classificação Estatística Internacional de Doenças e Problemas Relacionados à Saúde. 10a rev., 2008. Disponível em:

<http://www.datasus.gov.br/cid10/V2008/cid10.htm>. Acesso: 13 jul. 2017.

REIS, Maurício de Novais. Automutilação: um corte silencioso nos desejos. Teixeira de Freitas: Jornal Alerta, 2016 .

Estrutura básica da clínica: da medicina moderna à psicanálise. Rio de Janeiro, RJ, Psicanálise \& Barroco em revista, v.14, n. 02, dez. 2016b.

ROUDINESCO, Elisabeth; PLON, Michel. Dicionário de Psicanálise. Rio de Janeiro: Zahar, 1998.

SANTOS, Lucas Nápoli dos. A Doença como Manifestação da Vida: Georg Groddeck e um novo modelo de cuidado em saúde. Curitiba: Prismas, 2013.

TORRINHA, Francisco. Dicionário Latino Português. Porto: Junta Nacional de Educação, 1942.

ZIMERMAN, David E. Manual de técnica psicanalítica: uma re-visão. Porto Alegre: Artmed, 2004.

Recebido em: 02/08/2017.

Aceito em: 30/12/2017.

\section{POLÊM!CA $\mid$ LABORE}

